\title{
Vistas curtas, estórias sem fim: as convergências entre o popular e o infantil em "Campo geral", de Guimarães Rosa
}

\section{Rafael Eisinger Guimarães*}

\begin{abstract}
Resumo: A visão daqueles que vivem à margem em Abstract: The point of view of those who live both termos social e cultural é reconhecidamente um dos culturally and socially aside is well known as one of aspectos mais representativos da obra de João the most representative aspects in João Guimarães Guimarães Rosa. Nesse esforço de dar voz aos "ex- Rosa's work. In this effort to give voice to the "excêntricos", a criança e o sertanejo personificam um centric' the children and the "sertanejo" embody a way raciocínio totalmente distinto de uma assimilação of thinking that stands afar from a Cartesian cartesiana da realidade, raciocínio este tão caro à assimilation of reality, and which is very dear to the estética e ao pensamento rosianos. O presente texto tem rosian esthetic and ideas. The present paper has the por objetivo observar a forma como essas duas visões purpose of observing the way these two marginal views marginais convergem na figura de Miguilim, de Campo converge in the character Miguilim, from Campo geral, geral, ressaltando a importância que o ato de narrar showing the importance of the narrative act in the adquire no processo de percepção e interação desse process of perception and interaction between that personagem com o mundo que o cerca. character and the world around him.
\end{abstract}

Palavras-chave: João Guimarães Rosa; Miguilim; Keywords: João Guimarães Rosa; Miguilim; universo infantil; Walter Benjamin children's universe; Walter Benjamin

De todas as questões que marcam a obra de João Guimarães Rosa, duas se destacam como especialmente relevantes: as reiteradas representações dos universos sertanejo e infantil. Mais do que aspectos que se colocam lado a lado na prosa rosiana, pode-se dizer que o sertão, com seu modo específico de apreender e representar o mundo, muitas vezes se confunde com a concepção que os narradores de Rosa revelam ter acerca da visão e da lógica próprias dos meninos e das meninas. Por maiores que sejam as diferenças existentes entre um e outro, o sertanejo e a criança são peças fundamentais para aquilo que se identifica como o ponto central do pensamento desse autor: a valorização de uma outra forma de pensar, que não a excessivamente racional e cartesiana. Os "ex-cêntricos", aqueles que vivem à margem social ou cultural, assumem para Rosa um papel central, revelando o grande valor de uma forma de pensar tida como menor, quando não totalmente ignorada pela cultura de elite.

\footnotetext{
* Graduado em Comunicação Social pela Universidade Federal do Rio Grande do Sul (UFRGS), especialista em Literatura Brasileira pela Universidade do Vale do Rio dos Sinos (UNISINOS) e Mestre em Literatura Comparada pela UFRGS.
} 
Em Campo geral, talvez de uma maneira mais acentuada do que em qualquer outro texto de Rosa, é a figura de um menino - Miguilim - que personifica um olhar "outro" diante do mundo, olhar esse que está muito fortemente ligado ao ato de contar estórias. Como se fossem uma mesma ação, o compreender e o narrar diluem qualquer marca de diferença entre eles, de modo que a narrativa assume, muitas vezes, um movimento de idas e vindas aparentemente desconexas, assumindo a forma do labirinto que, para Walter Benjamin, conforme explica Jeanne Marie Gagnebin (1994), representa metaforicamente o pensamento infantil. Ao pensar sobre essa imagem construída pelo filósofo alemão, em uma contraposição ao trabalho de rememoração de Marcel Proust, GAGNEBIN (1994, p.99) atenta para um aspecto que acaba instaurando a diferença entre as reminiscências dos dois autores. Enquanto em Proust a memória é orientada por uma consciência e tem como forte característica a intenção, as lembranças de Benjamin são guiadas pela atenção, não tendo como objetivo a busca consciente de algo específico. Procurando marcar um pouco mais essa distinção, é possível, sem muito esforço, relacionar as idéias do primeiro a uma lógica cartesiana, ao passo que a concepção de Walter Benjamin afasta-se ao máximo de qualquer associação com o racionalismo tradicional. Nas palavras de GAGNEBIN (1994), o ato de recordar, para Benjamin, apresenta uma "renúncia à discursividade linear da intenção particular em proveito de um pensamento umständiich, ao mesmo tempo minucioso e hesitante, que sempre volta a seu objeto, mas por diversos caminhos e desvios, o que acarreta também uma alteridade sempre renovada do objeto" (GAGNEBIN, 1994, p.99). Mais do que a descrição desse olhar que vagueia, buscando e revelando sempre o diferente, o que se vê em Campo geral é materialização do labirinto benjaminiano na própria narrativa.

\begin{abstract}
Miguilim não gostava de pôr os olhos no escuro. Não queria deitar de costas, por que vem uma mulher assombrada, senta na barriga da gente. Se os pés restassem para fora da coberta, vinha mão de alma, friosa, pegava o pé. O travesseirinho cheirava bom, cheio de macela-do-campo. Amanhã, ia aparar água de chuva, tinha outro gosto. Repartia com o Dito. O barulho da chuva agora era até bonito, livre do moame do vento. Tio Terêz não tinha se despedido dele. Onde estava agora o Tio Terêz? Um dia, tempos, Tio Terêz o levara à beira da mata, ia tirar taquaras. (ROSA, 2001, p.50)
\end{abstract}

Como é possível observar, as percepções e os pensamentos de Miguilim parecem se dispersar, romper todo e qualquer limite de uma seqüência racionalmente imposta. Em poucas palavras, parecem voar livremente; o que confere aos pássaros que figuram ao longo de toda a novela uma significação toda especial.

Mas tio Terêz, de bom coração, ensinou-o a armar urupuca para pegar passarinhos. Pegavam muitos sanhaços, aqueles pássaros macios, azulados, que depois soltavam outra vez, porque sanhaço não é pássaro de gaiola. - "Que é que você está pensando, Miguilim?" - tio Terêz perguntava. - "Pensando em Pai..." - respondeu. Tio Terêz não perguntou mais, e Miguilim se 
entristeceu, porque tinha mentido: ele não estava pensando em nada, estava pensando só no que deviam de sentir os sanhaços, quando viam que já estavam presos, separados dos companheiros, tinha dó deles; (ROSA, 2001, p.29-30)

Além de ser um traço eminentemente estético, o "método do desvio" - para usarmos os termos de Walter Benjamin (BENJAMIN apud GAGNEBIN, op. cit. p.99) -, tido como característica central do pensamento infantil, marca a forma como Miguilim apreende a realidade que o cerca. Em Campo Geral, são os aspectos 'marginais', os acontecimentos considerados menores pelos adultos que ocupam o centro da trama. São eles o foco principal do olhar tanto do protagonista quanto do narrador, de certa forma relegando a um segundo plano o que se passa com os mais velhos. No entanto, como se pode observar, o fato de o narrador olhar a partir da perspectiva do menino não significa que aquele esteja alheio ao que acontece fora do universo infantil. Mesmo não representando o foco principal da narrativa, a trama que se desenrola na 'esfera adulta' é perfeitamente apreendida e compreendida tanto por ele quanto por Miguilim.

Mas Vovó Izidra vinha saindo de seu quarto escuro, carregava a almofada de crivo na mão, caçando tio Terêz. - "Menino, você ainda está aí?!" -; ela queria que Miguilim fosse para longe, não ouvir o que ela ia dizer a tio Terêz. Miguilim parava perto da porta, escutava. O que ela estava dizendo: estava mandando tio Terêz ir embora. Mais falava, com uma curta brabeza diferente, palavras raspadas. Forcejava que tio Terêz fosse embora, por nunca mais, na mesma da hora. Falava que por umas coisas assim é que há questão de brigas e mortes, desmanchando com as famílias. Tio Terêz nem não respondia nada. (ROSA, 2001, p.41)

- "Dito, eu fiz promessa, para Pai e Tio Terêz voltarem quando passar a chuva, e não brigarem, nunca mais..." "- Pai volta. Tio Terêz volta não." “-Como é que você sabe, Dito?" "- Sei não. Eu sei." (ROSA, 2001, p.49)

Longe de ser inferior, a visão da criança apresenta uma lógica própria, diferenciada, que, em muitos aspectos, escapa à compreensão dos adultos. No entanto, como observa GAGNEBIN (1994) a partir das reflexões de Benjamin, esse olhar "incompleto" e "deficiente" dos pequenos é revelador de verdades que os mais velhos não conseguem perceber. Aspectos que foram perdendo seu valor com o avançar da idade recuperam, aos olhos infantis, o caráter de novidade. A visão da criança aproxima-se da realidade sempre por outros caminhos, periféricos, marginais, percorrendo com prazer o labirinto simbólico de que fala Benjamin, o qual, como bem lembra GAGNEBIN (1994, p.105), representa "o outro lado da cultura, outro mas conjunto". Sobre esse aspecto, é interessante observar a importância que assume, para Miguilim, a opinião de Dito, que é um pouco mais novo que ele. Na lógica própria do protagonista, as palavras do irmão estão carregadas de uma sabedoria extraordinária, servindo quase sempre de orientação para suas atitudes. Na esteira dessa constatação, é possível arriscar a afirmação de que Dito personifica a mais pura essência do 
pensamento infantil, uma essência que Miguilim, apesar de ter apenas sete anos, vê por vezes desaparecer.

O Dito, menor, muito mais menino, e sabia em adiantado as coisas, com uma certeza, descarecia de perguntar. Ele, Miguilim, mesmo quando sabia, espiava na dúvida, achava que podia ser errado. Até as coisas que ele pensava, precisava de contar ao Dito, para o Dito reproduzir, com aquela força séria, confirmada, para então ele acreditar mesmo que era verdade. De donde o Dito tirava aquilo? (ROSA, 2001, p.98)

Mas agora Miguilim queria merecer paz dos passados, se rir seco sem razão. Ele bebia um golinho de velhice. (ROSA, 2001, p.89)

Afora todas as questões até aqui referidas, é preciso dar um destaque especial ao caráter simbólico que adquire a visão nesta obra de Guimarães Rosa. Se a percepção infantil, conforme referido anteriormente, é tida pelos adultos como essencialmente "deficitária", a "vista curta" de Miguilim parece acentuar esse aspecto negativo. Porém, o protagonista compensa a sua dificuldade em enxergar a longas distâncias com uma excelente visão dos detalhes e daquilo que os adultos classificariam como "futilidades". Nesse sentido, é bastante interessante observar também que o "problema" de visão de Miguilim, que pode ser metaforicamente associado à visão "marginal" da criança, é "resolvido" pelo doutor que vem de fora.

Mãe abaixava a cabeça, ela era tão bonita, nada não respondia. Parecia que Vovó Izidra tinha ódio de Mãe? (ROSA, 2001, p.48)

Tomezinho brincava de estralar as juntas dos dedos; depois, de puxar o nariz para diante. A Chica rezava alto, era a voz mais bonita de todas. Drelina parecia uma santa. Todos diziam que ela parecia uma santa. (ROSA, 2001, p.48-49)

E no mais ralhava sempre, porque Miguilim não enxergava onde pisasse, vivia escorregando e tropeçando, esbarrando, quase caindo nos buracos. (ROSA, 2001, p.127-128)

Depois Pai disse: - "Vigia, Miguilim: ali!" Miguilim olhou e não respondeu. Não estava vendo. Era uma plantação brotando da terra, lá adiante; mas direito ele não estava enxergando. (ROSA, 2001, p.130)

O senhor alto e claro se apeou. O outro, que vinha com ele, era um camarada. O senhor perguntava à Mãe muitas coisas do Miguilim. Depois perguntava a ele mesmo: - "Miguilim, espia daí: quantos dedos da minha mão você está enxergando? E agora?"

Miguilim espremia os olhos. Drelina e a Chica riam. Tomezinho tinha ido se esconder.

- Este nosso rapazinho tem a vista curta. Espera aí, Miguilim...

E o senhor tirava os óculos e punha-os em Miguilim, com todo o jeito.

- Olha, agora!

Miguilim olhou. Nem não podia acreditar! Tudo era uma claridade, tudo novo e lindo e diferente, as coisas, as árvores, as caras das pessoas. (ROSA, 2001, p.149)

Não obstante seus traços particulares, o universo infantil pode ser aproximado do popular em diversos aspectos, especialmente no que se refere à religiosidade, às superstições e às crendices. A relevância desses elementos no pensamento popular, apontada, entre outros, 
pelos estudos de Oswaldo Elias Xidieh (1993), pode facilmente ser estendida ao universo infantil. Contrárias à racionalidade que alicerça a cultura "letrada", as rezas e as crenças em santos e divindades fazem parte do imaginário e do cotidiano tanto das classes populares quanto das crianças. Assim, os elementos da esfera do mítico, que sempre tiveram espaço nas narrativas de Guimarães Rosa, apresentam uma importância redobrada em Campo geral, uma vez que a fé é, ao mesmo tempo, o escudo e o instrumento por meio do qual Miguilim se relaciona com a realidade.

Rezava, rezava com força; pegava um temor, até queria que brilhos doessem, até queria que a cama pulasse. Conseguia era outro medo, diferente. O Dito já tinha adormecido. O que dormia primeiro, adormecia. O outro herdava os medos, e as coragens. [...] Cuidava de outros medos. Das almas. Do lobishomem revirando a noite, correndo sete-portêlos, as sete-partidas. Do Lobo-Afonso, pior de tudo. (ROSA, 2001, p.92)

Tinha aprendido o segredo de uma coisa, valor de ouro, que aumentava para sempre seu coração. - "Dito, você sabe que quando a gente reza, reza, reza, mesmo no fogo do medo, o medo vai s'embora, se a gente rezar sem esbarrar?!" (ROSA, 2001, p.97)

“Ele vai morrer, Mãitina?!" Ela pegou na mão dele, levou Miguilim, ele mesmo queria andar mais depressa, entraram no acrescente, lá onde ela dormia estava escuro, mas nunca deixava de ter aquele foguinho de cinzas que ela assoprava. - "Faz um feitiço para ele não morrer, Mãitina! Faz todos os feitiços, depressa, que você sabe..." (ROSA, 2001, p.119)

Se, por um lado, o olhar infantil pode ser aproximado, em diversos aspectos, da lógica que rege o pensamento dito "marginal", por outro, não é possível se abster de relacionar um traço marcante na figura de Miguilim com algo que é igualmente característico da cultura popular. Trata-se do ato de narrar, no sentido que Walter Benjamin (1996) dá ao termo. Em seu texto $O$ narrador - considerações sobre a obra de Nikolai Leskov, o filósofo alemão identifica alguns aspectos definidores desse sujeito que, a seu ver, já não pode mais ser encontrado nos dias de hoje. Para o narrador nato, um sujeito essencialmente relacionado com a tradição oral, as estórias que conta estão sempre atreladas à realidade que lhe é próxima; para ele, narrar é algo que faz parte do seu dia-a-dia. Como observa BENJAMIN (1996, p.198), a "experiência que passa de pessoa a pessoa é a fonte a que recorrem todos os narradores.". Seja para aconselhar ou transmitir ensinamentos às novas gerações, seja para relatar experiências ou manter as memórias individual e coletiva, a narrativa oral tem sempre uma função utilitária.

Dentre todas as personagens de Campo geral, coube ao protagonista da trama a tarefa de desempenhar o papel do narrador benjaminiano. Para Miguilim, o ato de contar, seja o que ele viu e ouviu, seja o que ele imaginou, é muito mais do que uma simples brincadeira de criança. 
Quando voltou para casa, seu maior pensamento era que tinha a boa notícia para dar à mãe: o que o homem tinha falado - que o Mutúm era lugar bonito... A mãe, quando ouvisse essa certeza, havia de se alegrar, ficava consolada. Era um presente; e a idéia de poder trazê-lo desse jeito de cór, como uma salvação, deixava-o febril até nas pernas. (ROSA, 2001, p.28)

Mas então Miguilim fez de conta que estava contando ao Dito uma estória - do Leão, do Tatú e da Foca. Aí Tomezinho, a Chica e aquele menino o Bustica também vinham escutar, se esqueciam do presépio. E o Dito mesmo gostava, pedia: - "Conta mais, conta mais..." Miguilim contava, sem carecer de esforço, estórias compridas, que ninguém nunca tinha sabido, não esbarrava de contar, estava tão alegre nervoso, aquilo para ele era o entendimento maior. Se lembrava de seo Aristeu. Fazer estórias, tudo com um viver limpo, novo, de consolo. Mesmo ele sabia, sabia: Deus mesmo era quem estava mandando! - "Dito, um dia eu vou tirar a estória mais linda, mais minha de todas: que é com a Cuca Pingo-de-Ouro!..." O Dito tinha alegrias nos olhos; depois, dormia, rindo simples, parecia que tinha de dormir a vida inteira. (ROSA, 2001, p.114-115)

Walter Benjamin (1996) ainda atenta para o fato de que o narrador nato pode assumir duas formas bastante distintas.

'Quem viaja tem muito que contar', diz o povo, e com isso imagina o narrador como alguém que vem de longe. Mas também escutamos com prazer o homem que ganhou honestamente sua vida sem sair do seu país e que conhece suas histórias e tradições. (BENJAMIN, 1996, p.198).

$\mathrm{Na}$ esteira desse pensamento, é interessante observar que justamente um menino de sete anos que saiu uma única vez da região onde se criou - ou seja, alguém que possui traços diametralmente opostos àqueles que caracterizam os dois narradores arcaicos benjaminianos é quem possui a sabedoria para narrar.

Por fim, cabe ainda observar um outro aspecto do narrador tido como importante para Benjamin que, na novela de Rosa, assume uma significação especial. Como assinala o filósofo alemão, a narração e, por consequiência, a memorização do que é narrado, exigem "um estado de distensão que se torna cada vez mais raro" (BENJAMIN, 1996, p.204). Uma distensão que se traduz no inegável caráter lúdico e divertido que as narrativas assumem para Miguilim. A forte relação que se estabelece entre o ato de narrar e a própria infância parece ficar mais explicitada nos acontecimentos que sucedem à morte de Dito. Depois que morre seu irmão, Miguilim notoriamente se transforma. Seja pela imensa tristeza que toma conta de si, seja pela exigência do pai para que o menino comece a trabalhar, sua infância aos poucos vai se acabando. E o fato de não mais inventar e contar estórias, não por acaso, é o primeiro sintoma disso.

Daí por diante, não deixavam o Miguilim parar quieto. Tinha de ir debulhar milho no paiol, capinar canteiro de horta, buscar cavalo no pasto, tirar cisco nas grades de madeira do rego. (ROSA, 2001, p.126)

Nos outros dias, Miguilim não restou em folga de brincar com o Liovaldo, porque para a roça cedinho saía. [...]

Era légua e quarto, Miguilim tinha sono. Às vezes vinha dormindo em cima do cavalo. Por tudo, tinha perdido mesmo o gosto e o fácil poder de inventar estórias. (ROSA, 2001, p.131) 
Ao pensar na relação que se constrói entre o olhar, o contar e a narrativa de Rosa, parece importante, por fim, retomar as idéias de Sílvia de Menezes-Leroy (1997). A autora lembra que o sertão pode ser representado artisticamente pelo próprio sertanejo - sendo assim uma "arte do sertão" -, ou servir de tema à expressão artística de uma cultura "letrada" - ou seja, uma "arte sobre o sertão". Neste último caso, por se tratar de uma construção simbólica feita a partir de um olhar "de fora", não raramente as representações do espaço e do povo sertanejo são carregadas de estereótipos. Trata-se do sertão mítico, assim definido como o lugar do desconhecido, como o lugar "outro" do ponto de vista da cultura "erudita". Porém, como MENEZES-LEROY (1997) mesmo ressalta, é possível se identificar ainda um "terceiro" sertão, que não se refere ao espaço geográfico real nem à representação mais ou menos estereotipada que possa se fazer dele. Trata-se do sertão "como linguagem", ou seja, um fazer poético no qual o próprio trabalho do autor com as palavras confere ao texto uma "estética sertaneja".

Apontado por MENEZES-LEROY (1997) como um dos exemplos de uma escritura "esteticamente sertaneja", Rosa consegue, em seus textos, e, de um modo mais específico, em Campo geral, construir uma visão a partir da margem, a partir do universo "não-erudito", não obstante seu refinado trabalho de linguagem, que torna seu texto, às vezes, um tanto inacessível até para um sujeito "letrado". Assim, para muito além do aspecto lingüístico, a obra do escritor mineiro revela em sua base um "olhar diferente", uma lógica não-cartesiana que se pode atribuir tanto a um sujeito oriundo das culturas populares quanto a uma criança.

\section{Referências}

BENJAMIN, Walter. O narrador: considerações sobre a obra de Nikolai Leskov. In: Magia e técnica, arte e política: ensaios sobre literatura e história da cultura. 7.ed. São Paulo: Brasiliense, 1994. p.197-221.

GAGNEBIN, Jeanne Marie. A criança no limiar do labirinto. In: História e narração em Walter Benjamin. São Paulo: Perspectiva / FAPESP. Campinas: Editora da Universidade Estadual de Campinas, 1994. p.83-105.

MENEZES-LEROY, Sílvia. Como se faz um mito: o sertão como linguagem. In: CRISTÓVÃO, Fernando; FERRAZ, Maria de Lourdes; CARVALHO, Alberto (org.). Nacionalismo e regionalismo nas literaturas lusófonas. Lisboa: Cosmos, 1997. p.235240. 
ROSA, João Guimarães. Campo geral. In:) Manuelzão e Miguilim (Corpo de baile). 11.ed. Rio de Janeiro: Nova Fronteira, 2001. p.27-152.

XIDIEH. Oswaldo Elias. Narrativas populares: estórias de Nosso Senhor Jesus Cristo e mais São Pedro andando pelo mundo. São Paulo: Edusp. Belo Horizonte: Itatiaia, 1993. 